\title{
Multimodality therapy is recommended for limited-stage combined small cell esophageal carcinoma
}

\author{
Huan-Huan Wangl,* \\ Nicholas G Zaorsky ${ }^{2, *}$ \\ Mao-Bin Meng' \\ Zhi-Qiang Wu' \\ Xian-Liang Zeng' \\ Bo Jiang' \\ Chao Jiang' \\ Lu-Jun Zhao' \\ Zhi-Yong Yuan' \\ Ping Wang' \\ 'Department of Radiation Oncology, \\ CyberKnife Center, and Key \\ Laboratory of Cancer Prevention \\ and Therapy, Tianjin Medical University \\ Cancer Institute and Hospital, \\ National Clinical Research Center \\ for Cancer, Tianjin, People's Republic \\ of China; ${ }^{2}$ Department of Radiation \\ Oncology, Fox Chase Cancer Center, \\ Philadelphia, PA, USA
}

*These authors contributed equally to this work

Correspondence: Mao-Bin Meng; Zhi-Yong Yuan

Department of Radiation Oncology and CyberKnife Center, Key Laboratory of Cancer Prevention and Therapy, Tianjin Medical University Cancer Institute and Hospital, National Clinical Research Center for Cancer, Tianjin 300060, People's Republic of China

Tel +86 $222334 \quad 1405$

Fax +8622 2334 I 405

Email doctormm991@hotmail.com
This article was published in the following Dove Press journal:

OncoTargets and Therapy

13 February 2015

Number of times this article has been viewed

Background and aim: Limited-stage combined small cell esophageal carcinoma (LS-CSCEC) is a rare, poorly understood, underdiagnosed disease, with components of both small cell esophageal cancer and non-small cell esophageal cancer. We investigated the optimal treatment strategy and prognostic factors in patients with LS-C-SCEC.

Patients and methods: LS-C-SCEC patients included in the analysis (from our hospital and the literature) were treated between January 1966 and December 2013. Patient treatment strategies included surgery $(\mathrm{S})$, chemotherapy $(\mathrm{CT})$, and radiation therapy (RT). The primary end point was overall survival (OS); the secondary end points included tumor complete response rates, patterns of failure, and toxicity. Kaplan-Meier curves were compared with the log-rank test. Univariate and multivariate analyses were used to determine prognosticators for OS.

Results: A total of 72 patients were included in the analysis: 24 (33\%) from our hospital and $48(67 \%)$ from the literature. The median OS of all patients was 15.0 months. Patients who received CT had a significantly longer median OS than did those who did not (OS 22.8 months vs 10.0 months) ( $P=0.03$ ). Patients treated with multimodality therapy (including RT+CT [18\%], $\mathrm{S}+\mathrm{CT}[40 \%]$, or S+RT+CT [17\%]) vs monotherapy (typically, S [18\%]) had significantly improved OS (15.5 months vs 9.3 months) $(P=0.02)$ and complete response rates. On multivariate analysis, tumor location (upper third of the esophagus) and type of treatment (monotherapy) were the only factors predictive of poor OS.

Conclusion: Multimodality therapy (including $\mathrm{RT}+\mathrm{CT}, \mathrm{S}+\mathrm{CT}$, or $\mathrm{S}+\mathrm{RT}+\mathrm{CT}$ ) improves $\mathrm{OS}$ for patients with LS-C-SCEC compared with monotherapy (typically, S). Additional studies are necessary to personalize multimodal treatment approaches to individual patients.

Keywords: esophageal neoplasm, small cell, radiation therapy, surgery, chemotherapy

\section{Introduction}

The esophagus is the main site of extrapulmonary small cell carcinoma, and primary small cell esophageal carcinoma (SCEC) represents $1.0 \%$ to $2.8 \%$ of all esophageal cancers. ${ }^{1,2}$ The incidence of SCEC is highest in Southeast Asian countries, including Japan, Korea, and the People's Republic of China. ${ }^{3,4}$ SCEC is similar to small cell lung cancer (SCLC) in that both have a high frequency of regional and distant spread at time of diagnosis and a poor overall prognosis.,

The term "combined SCEC" (C-SCEC) is defined by World Health Organization (WHO) as SCEC with an additional component of non-small cell carcinoma, including squamous cell carcinoma, adenocarcinoma, or other carcinoma. Limited-stage (LS) C-SCEC (LS-C-SCEC) is currently considered a subset of SCEC, although biologic evidence to support this classification scheme is lacking. An accurate understanding of LS-C-SCEC is of great practical importance; its optimal treatment strategy may 
be different than that of pure SCEC, ${ }^{4,7-9}$ neuroendocrine esophageal carcinoma, ${ }^{10}$ or non-SCEC, ${ }^{11}$ akin to pure SCLC and combined SCLC (C-SCLC). ${ }^{12,13}$

Evidence behind the optimal therapeutic approaches to LS-C-SCEC is limited because of (1) the infrequency of the disease; (2) various treatment strategies (including surgery [S], chemotherapy [CT], radiotherapy [RT], and combinations of these treatments) have been reported to have similar outcomes; ${ }^{4}$ and (3) the prognosis for pure SCEC and C-SCEC is reportedly similar. ${ }^{4}$ Our previous study demonstrated that patients with pure LS-SCEC treated with RT+CT had an improved survival compared with those treated with $\mathrm{S}+\mathrm{CT} .{ }^{8}$ We believe LS-C-SCEC is a unique disease, and its optimal management may be different than that of LS-SCEC. Therefore, we performed a retrospective study to evaluate the clinical features, optimal treatment strategy, and prognostic factors in patients with LS-C-SCEC.

\section{Patients and methods}

\section{Study design and patient eligibility}

Eligible patients with LS-C-SCEC were recruited from our hospital and the literature. , $5,9,14-31$ The inclusion criteria were: (1) a pathological diagnosis of primary LS-C-SCEC; (2) treatment, including S, RT, CT, or a combination of these; and (3) a report of overall survival (OS) time. The exclusion criteria for patients were as follows: (1) a diagnosis of pure esophageal carcinomas (eg, squamous cell carcinoma, adenocarcinoma, or small cell carcinoma); (2) a diagnosis of extensive stage C-SCEC; (3) uncontrolled comorbid conditions (metabolic or psychiatric); and (4) an unreported OS time. The study protocol was in accordance with the ethical guidelines of the 1995 Declaration of Helsinki and was approved by independent ethics committees at Tianjin Medical University Cancer Institute and Hospital.

\section{Literature search strategy and data extraction}

We searched MEDLINE for patients treated for SCEC between January 1966 and December 2013. A preliminary search was designed to find all articles including the terms "small cell carcinoma" or "oat cell carcinoma" combined with "esophagus" or "esophageal." Three reviewers independently selected the patients and performed the data extraction, from these articles and their references. Discrepancies regarding stated information in articles were resolved by discussion among reviewers. All principal investigators who initially included these patients were contacted using the corresponding e-mail addresses listed in the respective studies. The message sent to the authors both acknowledged their original work and asked for permission to include their patients in the current study. Of the authors without functioning addresses, none objected to having his/ her patients included in the current study. Further, principal investigators were asked to supplement information that was missing from the original publication.

\section{Treatment schedule}

$\mathrm{S}$ was defined as radical resection of the primary tumor and/or local lymphadenectomy. RT was administered with conventional fields (two anterior-posterior opposed fields and two anterior-posterior [AP-PA] oblique opposed fields), three-dimensional (3D) conformal radiotherapy (3D-CRT), or intensity-modulated radiotherapy (IMRT). Data gathered about CT included agent(s) used and number of CT cycles.

\section{Outcome measurements and end points}

The primary outcome was OS. Secondary outcomes included tumor response rate (complete response [CR] and partial response [PR], clinically assessed at the time of follow up), pattern of failure (eg, locoregional recurrence [LRR] and distant metastasis [DM]), and treatment toxicity. OS was defined as the time between date of pathological diagnosis and date of death. The patients taken from literature who were alive at the reported time of communication were coded as being lost to follow up.

\section{Statistical analysis}

A $\chi^{2}$ test or Fisher's exact test were performed for qualitative data. OS curves were estimated by using the Kaplan-Meier technique and compared using the stratified log-rank test. Univariate analysis (UVA) and multivariate analysis (MVA) were performed using a Cox regression model. Predictors analyzed included sex, age ( $\leq 60$ vs $>60$ years), tumor location (upper vs middle vs lower third), tumor size ( $\leq 5 \mathrm{vs}>5 \mathrm{~cm}$ ), combined additional components (squamous cell carcinoma vs adenocarcinoma vs others, and their combinations), the number of additional histological components (one vs two or more), CT regimen (platinum- vs non-platinum-based), and type of treatment (monotherapy vs combination therapy). Data were analyzed using Intercooled Stata, version 8.2 for Windows (Stata Corp, College station, TX, USA), with a $P$-value of $<0.05$ considered significant.

\section{Results}

\section{Patient characteristics}

A total of 72 patients were included in the analysis: 24 patients (33\%) from our hospital and 48 patients (67\%) 
from 21 publications. ${ }^{2,5,9,14-31}$ The baseline characteristics of all patients are shown in Table 1. The characteristics of patients from our institution are summarized in Table 2. Among the 17 patients who underwent monotherapy, $13(18 \%)$ were treated with S, two (3\%) with CT, and two (3\%) with RT. A total of 55 patients underwent multimodality therapy, including 13 (18\%) patients who received CT+RT, $29(40 \%)$ who received $\mathrm{S}+\mathrm{CT}$, one $(1 \%)$ who received $\mathrm{S}+\mathrm{RT}$, and $12(17 \%)$ who received $\mathrm{S}+\mathrm{CT}+\mathrm{RT}$.

\section{Overall survival}

All patients were followed until death or December 2013.

The median follow-up time was 15.0 (range 3-108) months.

For the whole cohort, the median OS was 15.0 months; the 1-year, 2-year, and 3-year OS rates were 56\%, 39\%, and $27 \%$, respectively (Figure 1A). Compared with patients without $\mathrm{CT}$, patients with $\mathrm{CT}$ had significantly improved median OS (10.0 months vs 22.8 months) $(P=0.03)$ (Figure 1B).

Table I Patient characteristics

\begin{tabular}{|c|c|}
\hline & n (\%) \\
\hline \multicolumn{2}{|l|}{ Sex (72 available) } \\
\hline Male & $56(78)$ \\
\hline Female & $16(22)$ \\
\hline \multicolumn{2}{|l|}{ Age (years) (72 available) } \\
\hline$\leq 60$ & $25(35)$ \\
\hline$>60$ & $47(65)$ \\
\hline \multicolumn{2}{|l|}{ Tumor location ( 55 available) } \\
\hline Upper I/3 & $4(7)$ \\
\hline Middle I/3 & $42(76)$ \\
\hline Lower I/3 & $9(17)$ \\
\hline \multicolumn{2}{|l|}{ Tumor size (42 available) } \\
\hline$\leq 5 \mathrm{~cm}$ & $29(69)$ \\
\hline$>5 \mathrm{~cm}$ & $13(3 \mid)$ \\
\hline \multicolumn{2}{|l|}{ Combined additional components (72 available) $)^{+}$} \\
\hline Squamous cell carcinoma & $53(74)$ \\
\hline Adenocarcinoma & $6(8)$ \\
\hline Squamous cell carcinoma and adenocarcinoma & $\mathrm{I}(\mathrm{I})$ \\
\hline Others $^{\ddagger}$ & $10(14)$ \\
\hline Unknown & $2(3)$ \\
\hline \multicolumn{2}{|l|}{ The number of additional components (72 available) } \\
\hline I & $64(89)$ \\
\hline$\geq 2$ & $6(8)$ \\
\hline Unknown & $2(3)$ \\
\hline \multicolumn{2}{|l|}{ T classification (72 available) $)^{\S}$} \\
\hline cTI & $12(17)$ \\
\hline cT2 & $13(18)$ \\
\hline cT3 & $23(32)$ \\
\hline cT4 & I (I) \\
\hline Unknown & $23(32)$ \\
\hline \multicolumn{2}{|l|}{$\mathrm{N}$ status (72 available) $)^{\S}$} \\
\hline cNO & $34(47)$ \\
\hline $\mathrm{cNI}$ & $25(35)$ \\
\hline
\end{tabular}

Table I (Continued)

\begin{tabular}{|c|c|}
\hline & n (\%) \\
\hline Unknown & $13(18)$ \\
\hline \multicolumn{2}{|l|}{ TNM stage (72 available) $)^{\S}$} \\
\hline $\mathrm{cl}$ & $8(11)$ \\
\hline clla & $15(2 \mathrm{I})$ \\
\hline cllb & II (I5) \\
\hline clll & $17(24)$ \\
\hline Unknown & $21(29)$ \\
\hline \multicolumn{2}{|c|}{ Treatment types (72 available) } \\
\hline$S$ & $13(18)$ \\
\hline CT & $2(3)$ \\
\hline RT & $2(3)$ \\
\hline $\mathrm{CT}+\mathrm{RT}$ & $13(18)$ \\
\hline $\mathrm{S}+\mathrm{CT}$ & $29(40)$ \\
\hline $\mathrm{S}+\mathrm{RT}$ & $\mathrm{I}(\mathrm{I})$ \\
\hline $\mathrm{S}+\mathrm{CT}+\mathrm{RT}$ & $12(17)$ \\
\hline \multicolumn{2}{|l|}{ CT regimen (72 available) } \\
\hline Platinum-based* & $49(68)$ \\
\hline EP & $15(2 \mid)$ \\
\hline CE & $20(28)$ \\
\hline IP & $4(6)$ \\
\hline PF & $10(13)$ \\
\hline Non-platinum-based & $7(10)$ \\
\hline None & $16(22)$ \\
\hline \multicolumn{2}{|c|}{ \# of CT cycles (38 available) } \\
\hline$<4$ & $21(55)$ \\
\hline$\geq 4$ & $17(45)$ \\
\hline \multicolumn{2}{|c|}{ 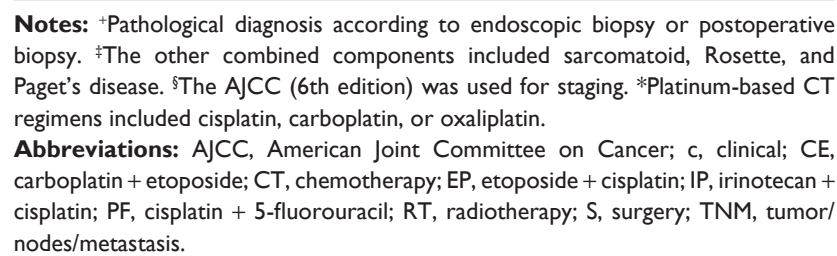 } \\
\hline
\end{tabular}

Patients who received multimodality therapy (eg, RT+CT, $\mathrm{S}+\mathrm{CT}, \mathrm{S}+\mathrm{RT}$, or $\mathrm{S}+\mathrm{RT}+\mathrm{CT}$ ) had significantly improved OS compared with those who received monotherapy with any technique (15.5 months vs 9.3 months) ( $P=0.02$ ) (Figure $1 C$ ). The survival time showed a slight trend towards superiority of $\mathrm{S}+\mathrm{CT}+\mathrm{RT}$ over $\mathrm{CT}+\mathrm{RT}$ or $\mathrm{S}+\mathrm{CT}$, although these differences were not statistically significant because of the small sample $(P=0.73)$ (Figure 1D).

\section{Tumor response and patterns of failure}

There were 56 patients had reported tumor response. A total $19(19 / 56$ [34\%]) and 37 patients (37/56 [66\%]) had a CR and PR, respectively. Among the 19 patients with $\mathrm{CR}$, the treatment modality was S alone (1/19 [5\%]), CT+RT (1/19 [5\%]), S+CT (12/19 [63\%]), and S+CT+RT (5/19 [27\%]). Among the 37 patients with PR, the treatment modality was S alone (11/37 [30\%]), CT+RT (2/37 [5\%]), S+CT (19/37 [51\%]), RT (1/37 [3\%]), and S+CT+RT (4/37 [11\%]). 


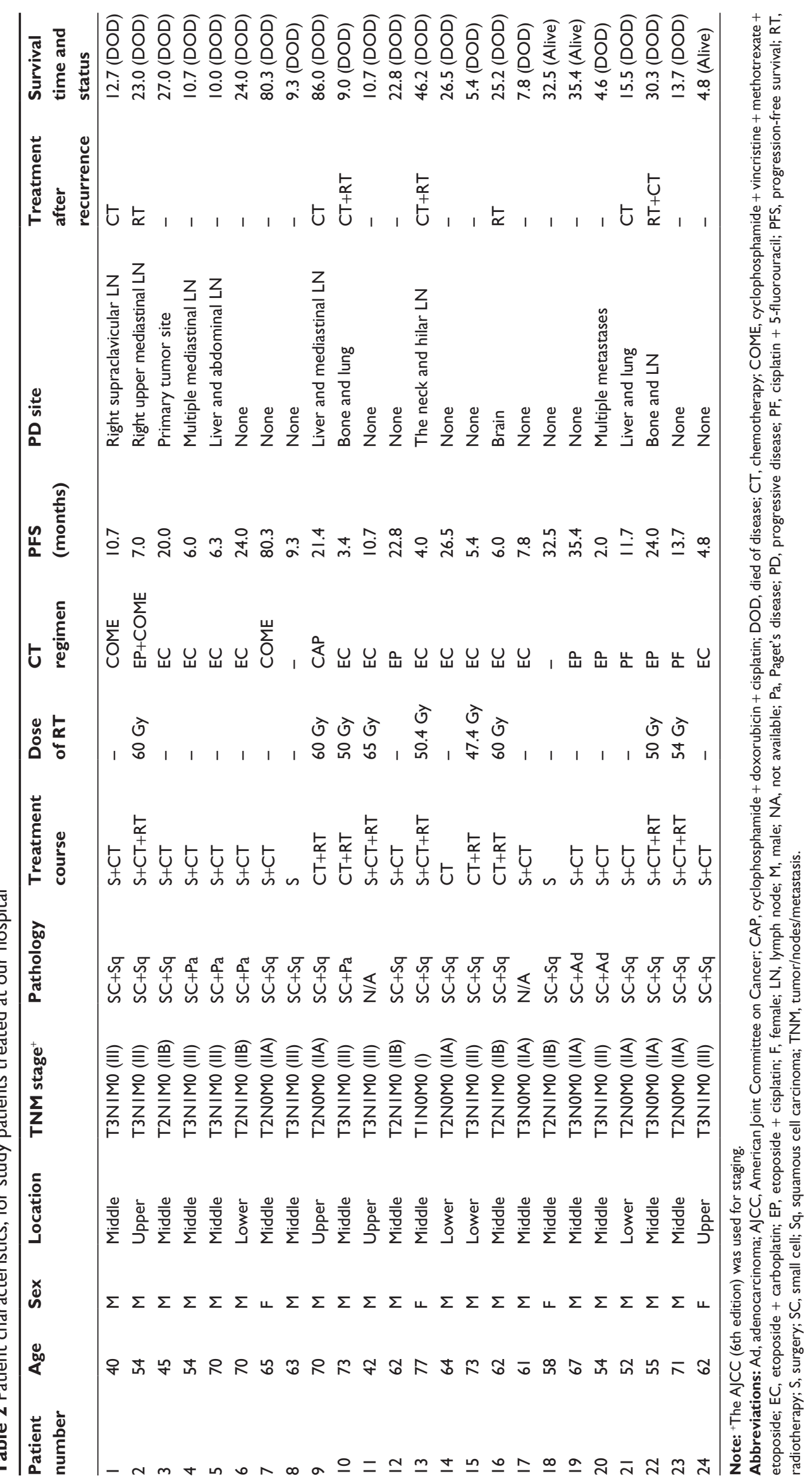




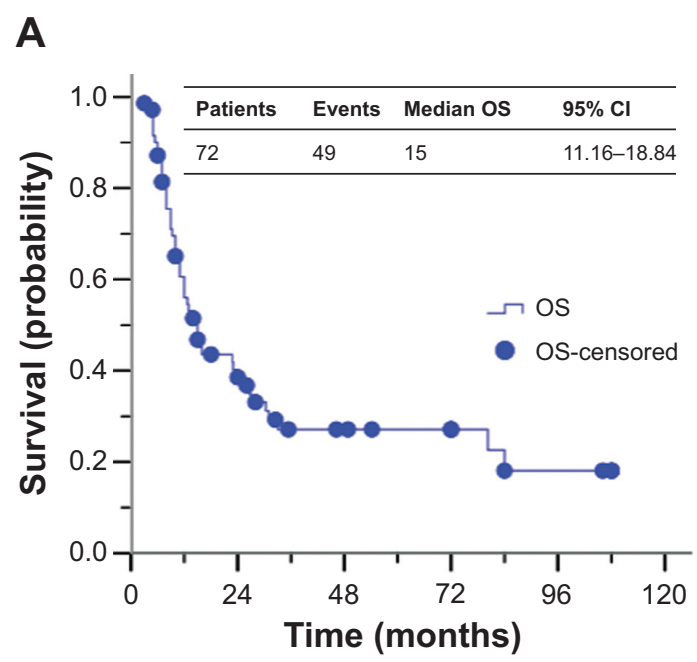

C

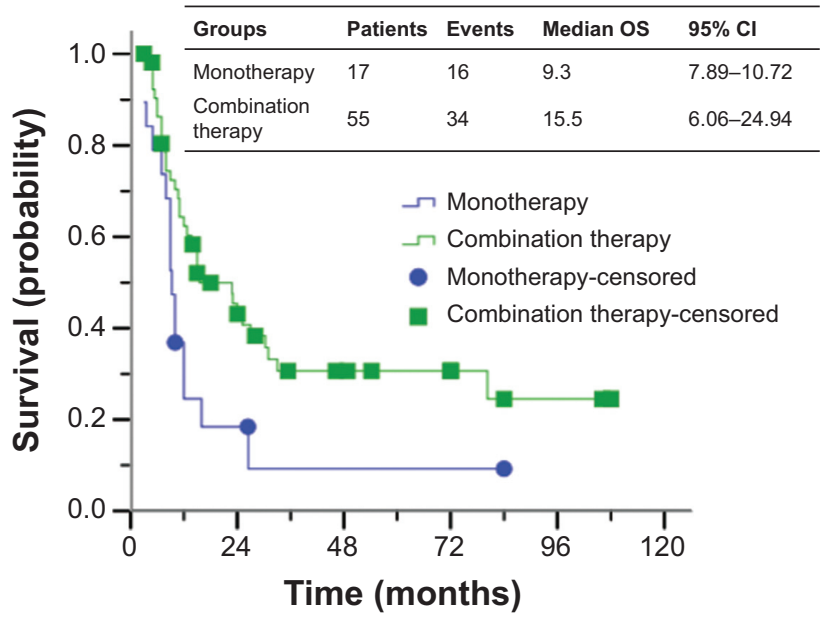

B
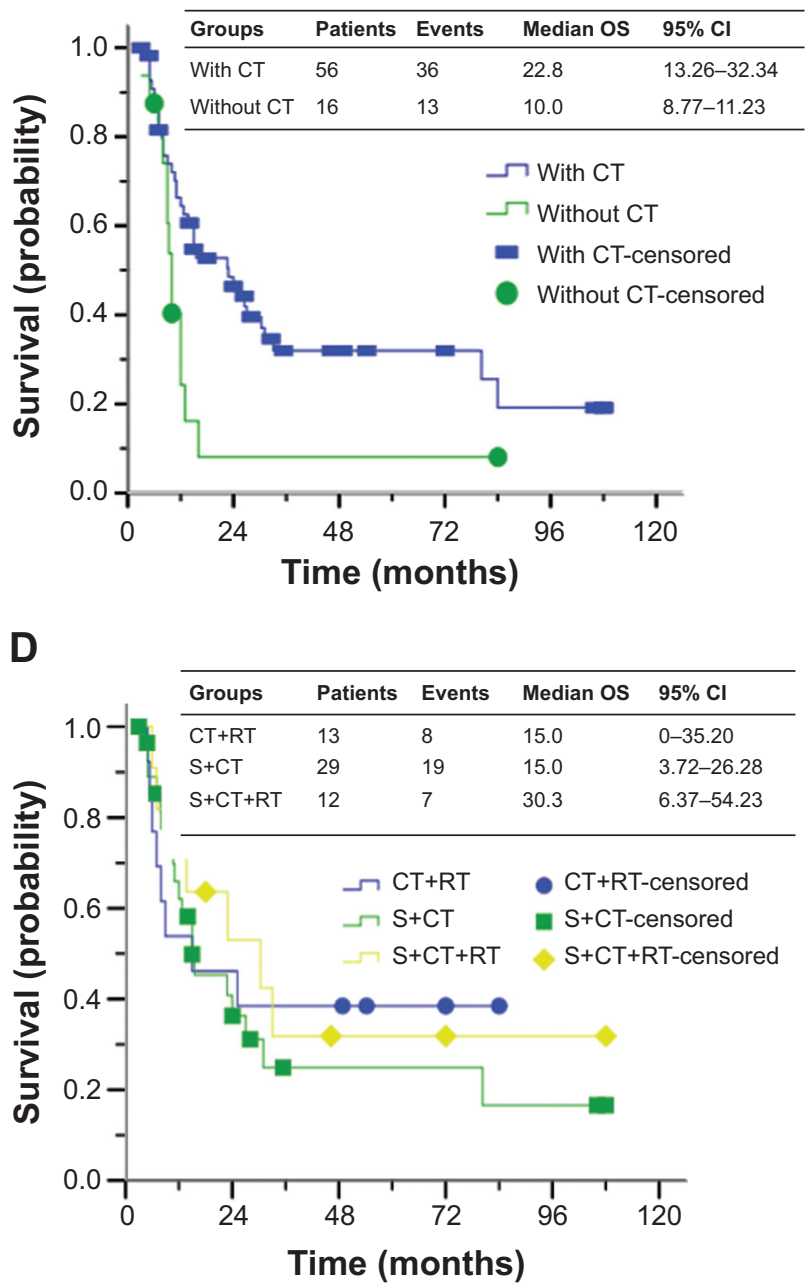

Figure I OS of patients with LS-C-SCEC.

Notes: (A) OS of all patients; (B) OS of patients with or without CT; (C) OS of patients who received monotherapy or multimodality therapy; and (D) OS of patients who received $\mathrm{CT}+\mathrm{RT}$, $\mathrm{S}+\mathrm{CT}$, or $\mathrm{S}+\mathrm{CT}+\mathrm{RT}$.

Abbreviations: Cl, confidence interval; CT, chemotherapy; LS-C-SCEC, limited-stage combined small cell esophageal carcinoma; OS, overall survival; RT, radiotherapy; S, surgery.

A total 25 patients $(25 / 72[35 \%])$ had reported patterns of failure: LRR without DM (8/44 [18\%]); DM without LRR (12/44 [27\%]); or LRR and DM (5/44 [11\%]). Of the 17 patients who had DM, the most frequent sites were liver (6/17 [35\%]), lung (3/17 [18\%]), lymph nodes (3/17 [18\%]), bone $(2 / 17[12 \%])$, brain $(1 / 17$ [6\%]), and diffuse metastasis $(2 / 17[12 \%])$.

\section{Prognostic factors}

Patient clinical characteristics were evaluated to determine their prognostic value in terms of OS. UVA indicated that sex, age, tumor size, tumor/nodes/metastasis (TNM) classification stage, types of histological components, number of histological components, and CT type were not associated with OS (Table 2). UVA and MVA revealed that tumor location (upper third of the esophagus) and type of treatment (ie, monotherapy) were associated with worse OS (Tables 3 and 4).

\section{Adverse events}

Of all patients, only five (5/72 [7\%]) patients had a reported adverse event secondary to treatment. All toxicities were minor (Radiation Therapy Oncology Group [RTOG] grade $\leq 2$ ) and included esophagitis, leukopenia, anemia, thrombocytopenia, and bone marrow suppression. And these toxicities were resolved with routine treatment.

\section{Discussion}

LS-C-SCEC is a rare subtype of SCEC. The optimal treatment strategy for LS-C-SCEC is controversial. Previous studies have suggested that pure LS-SCEC and LS-C-SCEC 
Table 3 Univariate analysis of the prognostic factors for survival in patients with LS-C-SCEC

\begin{tabular}{|c|c|c|c|c|c|}
\hline Characteristics & $\begin{array}{l}\text { MST } \\
\text { (months) }\end{array}$ & $\begin{array}{l}\text { I-year } \\
\text { OS (\%) }\end{array}$ & $\begin{array}{l}\text { 3-year } \\
\text { OS (\%) }\end{array}$ & $\chi^{2}$ & $P$-value \\
\hline \multicolumn{6}{|l|}{ Sex (72 available) } \\
\hline Female & 12.0 & 50 & 33 & 0.969 & 0.325 \\
\hline Male & 13.7 & 57 & 23 & & \\
\hline \multicolumn{6}{|l|}{ Age (years) (72 available) } \\
\hline$\leq 60$ & 22.8 & 54 & 27 & $0.04 I$ & 0.839 \\
\hline$>60$ & 12.7 & 58 & 25 & & \\
\hline \multicolumn{6}{|c|}{ Tumor location (55 available) } \\
\hline Upper I/3 & 7.0 & 9 & 0 & 28.84 & $0.000 I^{*}$ \\
\hline Middle I/3 & 24.0 & 67 & 30 & & \\
\hline Lower I/3 & 80.3 & 63 & 31 & & \\
\hline \multicolumn{6}{|l|}{ Tumor size (42 available) } \\
\hline$\leq 5 \mathrm{~cm}$ & 12.0 & 55 & 25 & 0.345 & 0.557 \\
\hline$>5 \mathrm{~cm}$ & 23.0 & 59 & 33 & & \\
\hline \multicolumn{6}{|l|}{ 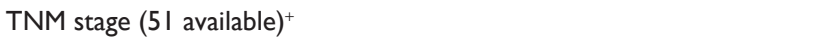 } \\
\hline $\mathrm{cl}$ & 15.0 & 63 & 38 & 2.325 & 0.508 \\
\hline clla & 12.0 & 43 & 22 & & \\
\hline cllb & 15.0 & 64 & 27 & & \\
\hline clll & 11.0 & 45 & 12 & & \\
\hline \multicolumn{6}{|c|}{ Combined additional components (70 available) } \\
\hline $\mathrm{Sq}$ & 12.7 & 55 & 21 & 1.054 & 0.788 \\
\hline Ad & 10.7 & 33 & 17 & & \\
\hline $\mathrm{Sq}+\mathrm{Ad}$ & 27.0 & - & - & & \\
\hline Others $\ddagger^{\ddagger}$ & 15.0 & 56 & 30 & & \\
\hline \multicolumn{6}{|c|}{ The number of additional components (70 available) } \\
\hline I & 12.7 & 55 & 21 & 0.742 & 0.389 \\
\hline$\geq 2$ & 27.0 & 60 & 30 & & \\
\hline \multicolumn{6}{|c|}{ Type of treatment (72 available) } \\
\hline Monotherapy & 8.0 & 23 & 0 & 30.83 & $0.000 I^{*}$ \\
\hline Combination therapy & 26.5 & 74 & 32 & & \\
\hline \multicolumn{6}{|l|}{ CT type (43 available) $)^{\S}$} \\
\hline Platinum-based & 12.7 & 57 & 27 & 1.133 & 0.287 \\
\hline Non-platinum-based & 10.0 & 33 & 0 & & \\
\hline
\end{tabular}

Notes: ${ }^{+}$The AJCC (6th edition) was used for staging. ${ }^{\text {*T The other combined }}$ components included sarcomatoid, Rosette, and Paget's disease. \$Platinum-based CT regimens included cisplatin, carboplatin, or oxaliplatin. $* P$-value $<0.05$.

Abbreviations: Ad, adenocarcinoma; AJCC, American Joint Committee on Cancer; CT, chemotherapy; LS-C-SCEC, limited-stage combined small cell esophageal carcinoma; MST, median survival time; OS, overall survival; Sq, squamous cell carcinoma; TNM, tumor/nodes/metastasis.

have similar behavior and outcomes, perhaps independent of treatment. ${ }^{4,32}$ However, most of these reports are relatively small retrospective series, and LS-C-SCEC has been included as a subset of patients with LS-SCEC. The current retrospective study demonstrated that LS-C-SCEC should be treated as a unique disease entity. Moreover, LS-C-SCEC patients who received multimodality therapy (which included CT) have significantly improved OS compared with patients receiving monotherapy.

Generally, the size of biopsy and presence of crush artifact, as well as number of study specimens taken by routine biopsy contribute to the underdiagnosis of C-SCEC.,33 In addition, change in histology during the treatment period also makes the diagnosis more challenging, ${ }^{34}$ akin to C-SCLC. ${ }^{35}$ In this study, the vast majority (55/72 [76\%]) of patients were diagnosed by postoperative pathology, which illustrates the importance of histopathological diagnosis. Therefore, it is postulated that the incidence of C-SCEC may be underestimated. In this study, the most frequent histological component was squamous cell carcinoma, in agreement with a previous report. ${ }^{36}$ The coexistence of pure SCEC with squamous cell carcinoma or other histologies in the same lesion is supported by the hypothesis that SCEC originates from amine precursor uptake and decarboxylation (APUD) cells or pluripotent stem cells. ${ }^{37}$

We believe that the rarity of LS-C-SCEC is the primary reason that there is a lack of consensus regarding its optimal treatment. From a clinical standpoint, our data indicate that LS-C-SCEC has historically been treated similar to non$\mathrm{SCEC}$, in that $\mathrm{S}$ has been an integral treatment approach for LS-C-SCEC (76\% of cases) and LS-SCEC. ${ }^{8}$ Additionally, we note that patients with pure LS-SCEC have significantly improved OS compared with LS-C-SCEC. ${ }^{8}$ The reason for this OS discrepancy is unclear and may be attributed to the fact that small cell carcinoma is typically more radiosensitive than non-SCEC or that the presence of a combined histology is secondary to multiple tumor cell lines.

Compared with LS-C-SCEC patients treated without CT, our results suggest that patients treated with $\mathrm{CT}$ have a significantly improved OS. We believe CT is a necessary treatment for both pure SCEC and C-SCEC, akin to patients with SCLC and C-SCLC. In addition, our study demonstrated that multimodality therapy (which includes CT) is associated with improved OS versus monotherapy. The survival time showed a slight trend towards the superiority of $\mathrm{S}+\mathrm{CT}+\mathrm{RT}$ over $\mathrm{CT}+\mathrm{RT}$ or $\mathrm{S}+\mathrm{CT}$, although these differences were not statistically significant because of fewer samples. Previous studies were consistent with our results, although these studies did not strictly focus on C-SCEC compared with other histologies. ${ }^{10,11,38}$

RT is important in the treatment of small cell carcinoma and non-small cell carcinoma of other disease sites. In this study, a total of 28 patients (28/72 [39\%]) received RT, either alone or in combination with $\mathrm{S}$ or CT. The indications and contraindications for RT (particularly as trimodality therapy with S and CT) in LS-C-SCEC should be evaluated in future prospective works.

Differences between pure SCEC and C-SCEC in terms of disease biology and pattern of metastatic spread constitute the subject of ongoing debate, and it is hypothesized that the C-SCEC has diverse biological characteristics that may influence tumor aggressiveness and treatment sensitivity. Our previous study demonstrated that the CRs were more 
Table 4 Multivariate Cox regression analysis of predictors for OS in patients with LS-C-SCEC

\begin{tabular}{|c|c|c|c|}
\hline Characteristics & HR & $95 \% \mathrm{Cl}$ & $P$-values \\
\hline Sex (male vs female) & 0.576 & $0.141-2.354$ & 0.443 \\
\hline Age ( $\leq 60$ vs $>60$ years) & 0.764 & $0.138-4.230$ & 0.758 \\
\hline Tumor size $(\leq 5 \mathrm{vs}>5 \mathrm{~cm})$ & 0.757 & $0.188-3.052$ & 0.696 \\
\hline Tumor location (upper I/3 vs middle I/3 vs lower I/3) & 0.210 & $0.057-0.770$ & $0.019 *$ \\
\hline TNM stage (cl vs clla vs cllb vs clll) ${ }^{+}$ & 1.009 & $0.517-1.969$ & 0.980 \\
\hline Combined additional components (Sq vs Ad vs Sq+Ad vs others) $)^{\ddagger}$ & 1.094 & $0.549-2.180$ & 0.798 \\
\hline The number of additional components ( $\mathrm{vs} \geq 2$ ) & 1.414 & $0.157-12.728$ & 0.757 \\
\hline Type of treatment (multimodality vs monotherapy therapy) & 0.063 & $0.005-0.731$ & $0.027^{*}$ \\
\hline CT type (platinum-based vs non-platinum-based) ${ }^{\S}$ & 1.469 & $0.332-6.510$ & 0.613 \\
\hline
\end{tabular}

Notes: *P-value $<0.05 .{ }^{+}$The AJCC (6th edition) was used for staging. ${ }^{\ddagger}$ The other combined components included sarcomatoid, Rosette, and Paget's disease. ${ }^{\text {\$Platinum-based }}$ CT regimens included cisplatin, carboplatin, or oxaliplatin.

Abbreviations: Ad, adenocarcinoma; AJCC, American Joint Committee on Cancer; Cl, confidence interval; CT, chemotherapy; HR, hazard ratio; LS-C-SCEC, limited-stage combined small cell esophageal carcinoma; OS, overall survival; Sq, squamous cell carcinoma; TNM, tumor/nodes/metastasis.

likely to be seen in patients with pure SCEC who received $\mathrm{RT}+\mathrm{CT}(100 \%)$ vs S+CT $(88 \%){ }^{8}$ in the current work, CRs were more likely to be seen in patients who received CT in combination with other treatment (18/19 [95\%]), but not RT and/or S (1/19 [5\%]). CT appears to be an important treatment modality for both pure SCEC and C-SCEC, as evidenced by rates of $\mathrm{CR}$ and $\mathrm{OS}$.

Interestingly, there was a significant difference in the pattern of failure (ie, LRR and DM) between pure patients with LS-SCEC (LRR and DM [76\%]) and LS-C-SCEC (LRR and $\mathrm{DM}[35 \%])$. The incidence of brain metastasis appears to be low in either disease; thus, prophylactic brain irradiation for LS-C-SCEC appears unnecessary.

Previous works have shown that the adverse prognostic factors for SCEC are advanced stage of the disease, tumor location, patient's performance status, and treatment type. ${ }^{2,5,9,14-31}$ In the present study, UVA and MVA identified two independent negative prognostic factors of LS-C-SCEC: tumor location (upper third of the esophagus) and type of treatment (monotherapy, which was typically, S). Additionally, although previous reports have identified the number of histological components to be predictive of outcome in C-SCLC, ${ }^{12,13,39}$ the present study did not identify histology (either count or subtype) as a predictor of outcome for LS-C-SCEC.

This study has potential weaknesses. First, it is retrospective and based largely on records kept by many institutions, which may have been heterogeneous in their diagnosis and management of patients. Second, the sample size of the present study may not have been optimal; however, LS-C-SCEC is a rare and likely underdiagnosed disease of patients, particularly during the past few decades when the patients were treated. Third, CT, RT, and S have differed widely and have evolved. Finally, some patient data were missing, and with a relatively small number of patients overall, we are unable to discuss the benefit of certain treatments (eg, concurrent vs sequential CT, or salvage therapy).

In conclusion, this study indicates that LS-C-SCEC is a unique disease that should be diagnosed and managed as an entity separate from LS-SCEC. Compared with monotherapy, multimodality therapy (which includes CT) is associated with improved OS for patients with LS-C-SCEC. We recommend that $\mathrm{S}+\mathrm{CT}+\mathrm{RT}, \mathrm{S}+\mathrm{CT}$, or $\mathrm{CT}+\mathrm{RT}$ should be considered as possible treatment approaches for LS-C-SCEC patients.

\section{Acknowledgments}

This work was supported by the National Natural Science Foundation of China (grant number 81201754), the New Teacher Fund for Doctor Station, the Ministry of Education (grant number 20121202120014), the National Natural Science Foundation of China (grant numbers 81472797 and 81201753), and the Foundation of National Clinical Research Center for Cancer (grant number N14B04).

In particular, we would like to acknowledge the work of Drs K Takubo, K Sasajima, SJ Walker, M Mori, I Muto, SR Craig, F Casas, T Nishimaki, AR Poynton, K Shimizu, M Mitani, GH Pantvaidya, H Makino, J Yamamoto, M Furihata, YP Yun, GY Yu, K Chin, F Bibeau, T Terada, and $\mathrm{J} \mathrm{Li}$. We also thank the anonymous referee for his/her very helpful comments, which remarkably improved the quality of this paper.

\section{Disclosure}

The abstract of this paper was presented at the American Society for Radiation Oncology 56th Annual Meeting as a poster presentation with interim findings. The poster's abstract was published in "Poster Abstracts" in the journal International Journal of Radiation Oncology Biology Physics. The full paper has never been published.

The authors report no conflicts of interest in this work. 


\section{References}

1. Huncharek M, Muscat J. Small cell carcinoma of the esophagus. The Massachusetts General Hospital experience, 1978 to 1993. Chest. 1995; 107(1):179-181.

2. Craig SR, Carey FA, Walker WS, Cameron EW. Primary small cell cancer of the esophagus. J Thorac Cardiovasc Surg. 1995;109:284-288.

3. Briggs JC, Ibrahim NB. Oat cell carcinomas of the oesophagus: a clinicopathological study of 23 cases. Histopathology. 1983;7(2):261-277.

4. Casas F, Ferrer F, Farrús B, Casals J, Biete A. Primary small cell carcinoma of the esophagus: a review of the literature with emphasis on therapy and prognosis. Cancer. 1997;80(8):1366-1372.

5. Pantvaidya GH, Pramesh CS, Deshpande MS, Jambhekar NA, Sharma S, Deshpande RK. Small cell carcinoma of the esophagus: the Tata Memorial Hospital experience. Ann Thorac Surg. 2002;74(6):1924-1927.

6. Brenner B, Tang LH, Klimstra DS, Kelsen DP. Small-cell carcinomas of the gastrointestinal tract: a review. J Clin Oncol. 2004;22(13): 2730-2739.

7. Lv J, Liang J, Wang J, et al. Primary small cell carcinoma of the esophagus. J Thorac Oncol. 2008;3(12):1460-1465.

8. Meng MB, Zaorsky NG, Jiang C, et al. Radiotherapy and chemotherapy are associated with improved outcomes over surgery and chemotherapy in the management of limited-stage small cell esophageal carcinoma. Radiother Oncol. 2013;106(3):317-322.

9. Takubo K, Nakamura K, Sawabe M, et al. Primary undifferentiated small cell carcinoma of the esophagus. Hum Pathol. 1999;30(2):216-221.

10. Maru DM, Khurana H, Rashid A, et al. Retrospective study of clinicopathologic features and prognosis of high-grade neuroendocrine carcinoma of the esophagus. Am J Surg Pathol. 2008;32(9):1404-1411.

11. Gamliel Z, Krasna MJ. Multimodality treatment of esophageal cancer. Surg Clin North Am. 2005;85:621-630.

12. Samson DJ, Seidenfeld J, Simon GR, et al; American College of Chest Physicians. Evidence for management of small cell lung cancer: ACCP evidence-based clinical practice guidelines (2nd edition). Chest. 2007; 132(3 Suppl):314S-323S.

13. Sgambato A, Casaluce F, Maione P, et al. Medical treatment of small cell lung cancer: state of the art and new development. Expert Opin Pharmacother. 2013;14(15):2019-2031.

14. Sasajima K, Hayashi N, Yamashita K, Onda M, Takubo K. Oat cell carcinoma of the esophagus with multiple differentiation. J Clin Gastroenterol. 1988;10(6):667-671.

15. Walker SJ, Steel A, Cullen MH, Matthews HR. Treatment of oesophageal small cell carcinoma by combined chemotherapy and surgical resection: report of two cases and review of published cases. Thorax. 1989;44(9):751-752.

16. Mori M, Matsukuma A, Adachi Y, et al. Small cell carcinoma of the esophagus. Cancer. 1989;63(3):564-573.

17. Muto I, Nishimaki T, Aizawa K, Suzuki T, Tanaka O, Hatakeyama K. Primary small cell carcinoma of the esophagus: report of a case. Surg Today. 1995;25(9):830-833.

18. Casas F, Farrús B, Daniels M, et al. Six-year follow-up of primary small cell carcinoma of the esophagus showing a complete response: a case report. Jpn J Clin Oncol. 1996;26(3):180-184.

19. Nishimaki T, Suzuki T, Nakagawa S, Watanabe K, Aizawa K, Hatakeyama K. Tumor spread and outcome of treatment in primary esophageal small cell carcinoma. J Surg Oncol. 1997;64(2):130-134.

20. Poynton AR, Walsh TN, Kelly A, Harney M, Stuart R, Daly PA, Hennessy TP. Small cell carcinoma of the oesophagus. Eur J Surg Oncol. 1997;23(6):509-512.

OncoTargets and Therapy

\section{Publish your work in this journal}

OncoTargets and Therapy is an international, peer-reviewed, open access journal focusing on the pathological basis of all cancers, potential targets for therapy and treatment protocols employed to improve the management of cancer patients. The journal also focuses on the impact of management programs and new therapeutic agents and protocols on
21. Shimizu K, Takiyama W, Mandai K, Tanada M, Kawabuchi Y, Heike Y. Undifferentiated carcinoma with lymphoid infiltration of the esophagus: a case report. Jpn J Clin Oncol. 1999;29(10):494-497.

22. Mitani M, Kuwabara Y, Shinoda N, Sato A, Fujii Y. Long-term survivors after the resection of limited esophageal small cell carcinoma. Dis Esophagus. 2000;13(3):259-261.

23. Makino H, Tajiri T, Onda M, et al. Effectiveness of preoperative chemotherapy using carboplatin (CBDCA) and surgery against an esophageal small cell carcinoma. Dis Esophagus. 2002;15(3):237-241.

24. Yamamoto J, Ohshima K, Ikeda S, Iwashita A, Kikuchi M. Primary esophageal small cell carcinoma with concomitant invasive squamous cell carcinoma or carcinoma in situ. Hum Pathol. 2003;34(11): 1108-1115.

25. Furihata M, Ono Y, Fujimori T, et al. Esophageal small cell carcinoma effectively treated by cisplatin and irinotecan. Esophagus. 2006;3(2): 61-64.

26. Yun JP, Zhang MF, Hou JH, et al. Primary small cell carcinoma of the esophagus: clinicopathological and immunohistochemical features of 21 cases. BMC Cancer. 2007;7:38.

27. Ku GY, Minsky BD, Rusch VW, Bains M, Kelsen DP, Ilson DH. Smallcell carcinoma of the esophagus and gastroesophageal junction: review of the Memorial Sloan-Kettering experience. Ann Oncol. 2008;19(3): 533-537.

28. Chin $\mathrm{K}, \mathrm{Baba} \mathrm{S}$, Hosaka $\mathrm{H}$, et al. Irinotecan plus cisplatin for therapy of small-cell carcinoma of the esophagus: report of 12 cases from single institution experience. Jpn J Clin Oncol. 2008;38(6):426-431.

29. Bibeau F, Chateau MC, Guiu M, et al. Small cell carcinoma with concomitant adenocarcinoma arising in a Barrett's oesophagus: report of a case with a favourable behaviour. Virchows Arch. 2008;452(1): 103-107.

30. Terada T, Maruo H. Esophageal combined carcinomas: Immunohoistochemical and molecular genetic studies. World J Gastroenterol. 2012;18(13):1545-1551.

31. Li J, Chen X, Shen Y, et al. A rare collision tumor of squamous carcinoma and small cell carcinoma in esophagus involved with separate lymph nodes: a case report. J Thorac Dis. 2013;5(5):E203-E206.

32. Kukar M, Groman A, Malhotra U, et al. Small cell carcinoma of the esophagus: a SEER database analysis. Ann Surg Oncol. 2013;20(13): 4239-4244.

33. Vos B, Rozema T, Miller RC, et al. Small cell carcinoma of the esophagus: a multicentre Rare Cancer Network study. Dis Esophagus. 2011; 24(4):258-264.

34. Fushimi H, Kikui M, Morino H, et al. Histologic changes in small cell lung carcinoma after treatment. Cancer. 1996;77(2):278-283.

35. Hage R, Elbers JR, Brutel de la Rivière A, van den Bosch JM. Surgery for combined type small cell lung carcinoma. Thorax. 1998;53(6):450-453.

36. Wang SY, Mao WM, Du XH, Xu YP, Zhang SZ. The 2002 AJCC TNM classification is a better predictor of primary small cell esophageal carcinoma outcome than the VALSG staging system. Chin J Cancer. 2013;32(6):342-352.

37. Ho KJ, Herrera GA, Jones JM, Alexander CB. Small cell carcinoma of the esophagus: evidence for a unified histogenesis. Hum Pathol. 1984; 15(5):460-468.

38. Zhu Y, Qiu B, Liu H, et al. Primary small cell carcinoma of the esophagus: review of 64 cases from a single institution. Dis Esophagus. 2014;27(2):152-158.

39. Babakoohi S, Fu P, Yang M, Linden PA, Dowlati A. Combined SCLC clinical and pathologic characteristics. Clin Lung Cancer. 2013;14(2): 113-119.

\section{Dovepress}

patient perspectives such as quality of life, adherence and satisfaction. The manuscript management system is completely online and includes a very quick and fair peer-review system, which is all easy to use. Visit http://www.dovepress.com/testimonials.php to read real quotes from published authors. 